\title{
PERSPECTIVAS CONSTITUCIONALES DEL DERECHO SOCIAL COLECTIVO ${ }^{1}$
}

\author{
Manuel María Zorrilla Ruiz \\ Catedrático de la Universidad de Deusto \\ Presidente del Tribunal Superior de Justicia del País Vasco
}

\begin{abstract}
Sumario: 1. Adecuación de las relaciones de trabajo al Estado social y democrático de Derecho. 2. Elevación de los derechos sociales al rango de derechos fundamentales. 3. Dimensiones constitucionales de la justicia social. 4. Protagonismo y relieve constitucional del sindicato. 5. Repercusiones del pluralismo político en el Derecho Social. 6 Ambientación constitucional de las libertades sindicales. 7. Adelanto y estimulo de las libertades sindicales. 8. Interacciones del ordenamiento sindical y el ordenamiento jurídico del Estado. 9. Perpetuación de la cláusula transformadora y social. 10. Dinamismo de la transformación. 11. Reflejo constitucional de la autotutela colectiva. 12. Conclusión. Abreviaturas y siglas
\end{abstract}

\section{Adecuación de las relaciones de trabajo al Estado social y democrático de Derecho}

El Estado social y democrático de Derecho -en que, sin la constancia de un poder constituyente visible, España se ha erigido- responde tardíamente, ante las demoras históricas que impidieron su tempestiva implantación, al llamamiento moralizador que, a mediados del siglo XX, reclama la atención de los países industrializados con economía de mercado. El nuevo modelo de Estado socializa los derechos individuales de corte clásico - corrigiendo los defectos que acusaba el Estado demoliberal - y refuerza, como derechos subjetivos y situaciones jurídicas accesibles a la jurisdicción, los que hasta entonces eran intereses sociales desnudos y carentes de acción procesal. Intereses,

${ }^{1}$ Estas reflexiones, relacionadas con la formación y los valores que el Prof. Dr. D. Pablo Lucas Verdú ha inculcado a muchas generaciones de estudiosos, evocan nostálgicamente las actividades del Aula Juan XXIII —que, durante la lejana década de los años 60, auspiciaron, en la Universidad de Deusto, el homenajeado y el Prof. Dr. D. Antonio Beristain e Ipiña- y la amistad mantenida, andando el tiempo, con quien ahora recibe el reconocimiento que tan justamente merecen su sabiduría, su condición de persona de bien y su entrega a la causa de la Universidad. 
primero ignorados por el Estado de Derecho liberal burgués y deformados, más tarde, por los regímenes autoritarios de Occidente (arts. 1.1 y $9.1 \mathrm{CE})$.

La idea de que el Estado social sea también Estado de Derecho traza la línea de separación con la actitud indiferente que caracterizó al Estado demoliberal. El ordenamiento jurídico que disciplinaba las experiencias de una sociedad formada por la suma numérica de los individuos que poblaban en el territorio de la soberanía del Estado, se consideraba liberal, porque hacía caso omiso del tratamiento de la lucha de clases y prescindía de juridificar — sometiéndolos al imperio de la ley y el Derecho- las cuestiones más álgidas del conflicto industrial. El Derecho del Estado demoliberal no aspiraba a racionalizar los aspectos colectivos que surgían de los contactos de la clase dominante establecida con la nueva clase desprotegida y emergente, cuyos problemas quedaban fuera del proyecto de organización de la sociedad en el Estado. Las consecuencias y expresiones de la lucha de clases se trasladaron a los escenarios represivos del Derecho penal o de la legislación de orden público. Si el Estado social se dice hoy de Derecho, no es porque las fuerzas sociales — responsables de su edificación- compartan la idílica teoría de la irresistibilidad de las acciones de su ordenamiento jurídico, sino porque - conscientes de los enrarecimientos que engendra la supervivencia del conflicto industrial - entienden que, so pena del desvanecimiento de su imperio, el Derecho debe tomar las medidas de regulación mínima, control y apoyo que, mitigando la causticidad de ese conflicto, aseguran el equilibrio inestable que su naturaleza requiere. Situación que se significa por una relación civilizada de las organizaciones sindicales y los empleadores en la sociedad pluralista, y por la efectiva posibilidad de que, sin merma de sus identidades respectivas, acrediten la capacidad de mantener su predisposición cooperativa. De esta contribución se benefician la subsistencia de los procesos productivos, el crecimiento gradual de la riqueza, la protección de los intereses de la economía general, la garantía del funcionamiento de los servicios esenciales de la comunidad y la cooperación de los poderes públicos a una Política Social que, sin alcanzar el pleno empleo, contrae la obligación — de medios y no de resultado- de orientar en esa dirección su movilidad y su estrategia (art. $40 \mathrm{CE}$ ).

La rotulación de Estado social y democrático de Derecho responde, no obstante su apariencia tautológica, a la finalidad de subrayar que la nueva forma política del Estado español - a saber, la Monarquía Parlamentaria - nada tiene que ver con la figura del Estado social y autocrático de Derecho del previgente sistema autoritario. Aunque lo social implica un concepto sintético y omnicomprensivo de los valores demo- 
cráticos, la precisión es necesaria ante lo irrepetible del fenómeno del tránsito del paternalismo autoritario al sistema civil de libertades. La técnica y la tónica de tal aventura eludieron - por inmisericordes y poco inteligentes - las soluciones basadas en la ruptura y, para justificar su preferencia reformista, recurrieron a un uso alternativo del Derecho. La democraticidad del Estado social le separaba de las falsificaciones que antes habían adulterado su concepto, degradándole a un instrumento de expansión económica, al servicio de un sentimiento nacional desmedido y olvidadizo del valor de la dignidad de la persona humana (arts. 1.1 y 3 , y $10.1 \mathrm{CE}$ ).

\section{Elevación de los derechos sociales al rango de derechos fundamentales}

La invocación de la igualdad material — que acomoda el sentido de la cláusula transformadora y social a las dimensiones de una libertad que reconoce y elogia- permite mejorar la suerte de algunas situaciones de Derecho Social que se aprovechan - porque su tratamiento equitativo así lo exige - de una protección más enérgica que la debida a su posición originaria. Ello salva el demérito de derechos sociales cuya tutela — no máxima y sí de proporciones módicas - era escasa en vista del énfasis con que el encabezamiento de la legalidad fundamental proclama la emergencia del Estado social y democrático de Derecho (arts. 1.1, 9.2, 14, 35.1 y $41 \mathrm{CE}$ ).

Otro tanto cabe decir del derecho fundamental a una efectiva tutela judicial, cuya respuesta - consistente en un razonamiento motivado y persuasivo frente a las cuestiones planteadas ante el orden social de la jurisdicción - purga muchos de los reparos que se han hecho valer (art. 24.1 CE).

Ambas posibilidades emanan de un sugestivo concurso de normas, por el que - ante la eventualidad de que la misma situación encaje en la regla jurídica de origen o en otra más flexible - se opta por la segunda, cuya naturaleza omnicomprensiva consigue efectos protectores más directos que los de la ordenación propia del caso. La solución se pliega a la naturaleza de las cosas y a los imperativos del valor superior del ordenamiento jurídico en que la justicia — resumen de la igualdad que estimula y de la libertad que compromete- se hace consistir. Este manejo alternativo del Derecho - que trae causa de la cláusula de transformación - ha mejorado la suerte de ciertos derechos y principios sociales que extravagaban formalmente del marco de los derechos fundamentales y de las libertades públicas (arts. 1.1, 9.2 y 24.1 CE). 
Amén de las razones —más recientes- que avalan el carácter fundamental de la libertad de empresa, la técnica aludida - a saber, el concurso ideal de normas constitucionales- permite asignarle ese carácter con base en el reconocimiento y garantía de las libertades públicas de producción y creación técnica. El signo de los tiempos ha superado el caduco simplismo de la competencia industrial y mercantil, y ha convertido la iniciativa empresarial en la conjura y superación de una masa de riesgos que, a su carácter extraordinario, añaden las funciones sociales inherentes a las renovadas exigencias de las relaciones de trabajo (arts. 9.2, $20.1 b, 33.2$ y $38 \mathrm{CE}$ ).

El orden público - afectado por las tensiones del conflicto industrial - prosigue limitando la actuación de los derechos ejercitables con motivo de las actividades productivas. La mención que, a propósito de un concreto derecho fundamental, le dedica el constituyente, se predica de todos los derechos y libertades de esa naturaleza y coincide con la noción de paz social a que también se apela. Las vicisitudes del conflicto industrial conmueven dicha paz con más intensidad que las de otros conflictos habidos en el seno del pluralismo social (arts. 10.1 y $16 \mathrm{CE})$.

La seguridad - a que toda persona tiene derecho- admite diferentes versiones, sin exceptuarse la que, como compromiso del Estado de Bienestar, lleva el nombre de Seguridad Social. Su puesta a cargo de los poderes públicos esboza, por hipótesis, uno de los derechos fundamentales que asisten a todas las personas físicas agrupadas en las comunidades naturales. El carácter fundamental del derecho a la Seguridad Social — variante del derecho general a la seguridadno casa con la consigna reductora que ha inspirado la enumeración de los principios rectores de la política social y económica (arts. 18 y $41 \mathrm{CE})$.

Cabe alegar, además de los argumentos indicados, otros —más novedosos y actuales - en pro del carácter fundamental de los derechos sociales. La obligación - que incumbe a la UE y a los Estados miembros- de conseguir una protección social adecuada, supone - no de manera tácita y sí a tenor de una concluyente manifestación- que, al reaccionarse así, se tengan presentes los derechos sociales fundamentales enunciados en la CSE y los que después ha sancionado la CCDSFT, texto comunitario que alude intencionadamente a los derechos fundamentales de los trabajadores. El Derecho objetivo de cualquiera de los Estados miembros no puede, so pena de vulnerar el principio de primacía del Derecho Comunitario, rebajar el rango de una institución a la que las normas europeas adjudican superior condición o dispensan una tutela más enérgica que la que, en paralelo, le ha otorgado la legalidad 
constitucional u ordinaria del Estado. El reconocimiento de esta naturaleza exige, como máximo, proceder a una reforma constitucional que vuelque los derechos sociales en el depósito de los derechos fundamentales, y, como mínimo, una reacción de los poderes públicos que, acatando lo exacto de la calificación, inapliquen las normas que la contradigan (arts. 9.3 CE y 136 I VCTR).

La técnica del concurso de normas es útil para adjudicar la cualidad de derechos fundamentales a ciertas expresiones de la participación en el gobierno de la empresa. No en vano, se reconoce y acepta, desde esa perspectiva, el derecho a comunicar o recibir información veraz por medios de difusión que incluyen las variantes de comunicación relativas a ese particular (arts. 20.1 b, 38 y 129.2 CE).

Las formas de representación unitaria en los lugares de empleo o centros de trabajo, provienen de un sindicalismo dispuesto a combatir los abusos del poder de organización que violan los derechos constitucionales de los trabajadores y la conmutatividad de sus relaciones contractuales. Sus orígenes - típicos de la espontaneidad de la democracia directa- y el tránsito a modelos, más perfectos, de democracia delegada, no destituye a estas acciones de su pertenencia al elenco de libertades sindicales, ni las priva de la protección cualificada que les corresponde (arts. 53.2, 129.2 CE).

La conversión en derecho fundamental del derecho al trabajo de los condenados a penas de privación de libertad, representa —más que una norma tendente al tratamiento de las relaciones de trabajouna pauta metodológica del proceso de su readaptación social. Una vez reinsertados en la comunidad de origen o en otra a la que transfieren, soportarán, en condiciones iguales a las del común de los demandantes de empleo, los riesgos de un mercado acosado por la escasez de ocupación y las dificultades de la demanda de trabajo. La resocialización penitenciaria es el plus que compensa la marginación social a que se exponen durante el cumplimiento de la pena, si se piensa en los inconvenientes del futuro que, una vez liberados, van a compartir (arts. 25.2, 35.1 y $40 \mathrm{CE}$ ).

El derecho a la libertad de empresa también adquiere el trato de derecho fundamental, porque - si, de nuevo, se atiende al principio de primacía del Derecho Comunitario- cuesta admitir conceptualmente que el óptimo de protección de la libre circulación de capitales y la libertad de establecimiento - derechos intangibles de las comunidades - resulte agrietada por la consideración constitucional - menos generosa - que un Estado miembro dedique a la libertad de iniciativa económica en el mercado de libre concurrencia (arts. $38 \mathrm{CE}$ y 136 I VCTR). 


\section{Dimensiones constitucionales de la justicia social}

La justicia social — síntesis de la igualdad que libera a la persona individual y de la libertad que engrandece sus intereses legítimosconstituye un valor superior que no acampa fuera del ordenamiento jurídico, ni se limita a inspirar su contenido y su factura. Pertenece a la interioridad del Derecho objetivo y prepondera sobre los principios y preceptos constitucionales subordinados a las directrices - bien reconocidas, bien atisbadas en el horizonte histórico de la razón prácticaque forman un bloque de yusnaturalismo latente. Este acervo de moralidad legalizada - trasunto del Derecho de Gentes de las relaciones de trabajo- se localiza en el vértice de la figura piramidal del ordenamiento que le representa (art. 1.1 CE).

El Estado social - cuya adjetivación embebe la nota de democraticidad - es Estado de Derecho, porque el Estado demoliberal se satisfizo con racionalizar jurídicamente las condiciones inorgánicas de la sociedad de su tiempo, mientras que el Estado moderno quiso eliminar esos defectos y cumplió la obligación eticopolítica de responder a los retos del conflicto social. Al ser éste el más álgido de cuantos confluyen en los movimientos de la sociedad orgánica, la acción de los poderes públicos propende a asegurar la paz social, sin atentar contra el valor de la justicia ni minorar el contenido esencial de las libertades sindicales. Compensa, con acciones de apoyo, las exigencias de control que imponen los intereses generales de la soberanía estatal y del resto de los derechos constitucionales — inherentes a la condición de la persona, anteriores a las leyes humanas y obligatorios para el legisladorque son objeto de reconocimiento positivo (arts. 1.1, 9.2 y 10.1 CE).

La justicia social nunca es una justicia felizmente lograda y poseída, porque permanece a la espera de alcanzar su deseable y lejana plenitud. Así resulta del compromiso consistente en propugnarla, que no es un infinitivo triunfalista, sino la confesión sincera de las dificultades que acarrea la busca de la tierra prometida y de los obstáculos que aquejan a esta aventura de progreso. Su axiología concurre con las Políticas Sociales que - figurando, por derecho propio, en cualquier programa ideológicamente definido- pueden diferir y de hecho difieren. Así lo autorizan e incluso lo quieren las divergencias o matices que la elasticidad del pluralismo político permite adoptar (arts. 1.1, 40.1 y 149.1 nums. $7 .^{\circ}$ y $\left.17 .^{\circ} \mathrm{CE}\right)$.

El Derecho Social acampa en una de las parcelas del ordenamiento jurídico del Estado. Sector que no deja de someterse a los valores superiores que se han enunciado y, en especial, a la justicia que los acapara y agrupa. Esta porción del ordenamiento jurídico vincula, de una parte, 
a los ciudadanos que han de acatar sus mandatos y prohibiciones, $\mathrm{y}$, de otra, a los poderes públicos, cuya estructura y extensión actuales desbordan el tradicional achicamiento de los poderes clásicos -legislativo, ejecutivo y judicial- relacionados en régimen de separación e independencia (arts. 1.1, 9.1, 66.2, 117.1 y 4, 161.1 $a$ y $163 \mathrm{CE}$ ).

La mención del valor superior del pluralismo político trasluce la evidencia histórica de que - al precio de las transacciones que el texto constitucional ha hecho suyas- interviene la voluntad conciliadora y confiada en que la hospitalidad de la ley fundamental acoja cuantas orientaciones ideológicas comparten unos mínimos indulgentes y accesibles. Mínimos que, aún en los temas de Política Social, la acción pacificadora del constituyente cuida de coordinar para evitar disgregaciones inconstitucionales o tentativas rupturistas (art. 1.1 CE).

\section{Protagonismo y relieve constitucional del sindicato}

El constituyente concibe el sindicato como un concepto jurídico indeterminado que se concreta en las formas históricas de cada trance de acción y de progreso. El sindicato ha sido y sigue siendo una comunidad organizada que preordena sus medios y fines a la protección de los intereses colectivos que comparten sus fundadores y cuantos se adhieren al proyecto iniciado. El sindicato tradicional surge a consecuencia de la violación de los intereses sociales de la nueva clase, de una reacción estimulada por las enseñanzas de la historia, de la conciencia de solidaridad que repugna esas agresiones, del propósito de agotar la protección a que se aspira y de la eficiencia de los recursos de que se dispone. Recursos que, ante la expansión del pluralismo social, hacen del sindicato el principal de sus poderes de hecho y facilitan la gestión, en el seno del conflicto industrial, de las reivindicaciones que proceden de las demandas sociales o se incorporan, por determinación del sindicato, al acervo de sus libertades de origen (art. $7 \mathrm{CE}$ ).

El sindicato clásico operaba en los vastos espacios de las comunidades y Estados democráticos de Derecho que, a cambio de su renuncia a la revolución, le aceptaban y favorecían en los ámbitos de su soberanía. Ahí se escenificaban los antagonismos — de amplio espectro-que enfrentaban al capital y al trabajo, divididos antes por el radicalismo de la lucha de clases y separados luego por el conflicto industrial que, pese a constituir su versión civilizada, seguía ocupando la comunidad más convulsa de la sociedad pluralista (arts. 9.2, 10.1, 28.2 y 37.2 CE).

El sindicato clásico se encuentra desarmado cuando las agresiones causadas por la promoción de las técnicas de productividad — atractivo 
y fruto perverso de la racionalización de los procesos industrialesmudan la sede del conflicto industrial. La elusión de las connotaciones de orden público requiere abandonar los grandes espacios sociales y trasladar el conflicto a las unidades productivas, donde las nuevas formaciones sindicales - más avisadas y ágiles que el sindicato clásicose van asentando. Las unidades o centros de empleo - coordinados por la racionalización productiva - eran poco accesibles a los controles sindicales, lastrados por un pasado de conflictividad escasa, de interlocución fácil con los agentes sociales y de afortunadas actividades de gestión. El concepto jurídico indeterminado de sindicato se reconstruye en consonancia con las realidades industriales recién diagnosticadas. Se desencadena un cambio imprevisto y aparecen problemas propios de una crisis en que los útiles tradicionales se tornan inservibles y el futuro diseña interrogantes de difícil adivinación y despeje (arts. 7, 9.2, 10.2 y $129.2 \mathrm{CE}$ ).

Los intereses colectivos - que comprometen las reacciones de la nueva morfología sindical- postulan la defensa de los derechos constitucionales de los trabajadores — ciudadanos de segunda zona que devienen cautivos de las demasías de la organización- y la conmutatividad contractual que, a punto de engendrar obligaciones de resultado donde hay sólo deuda de actividad, soporta el alza despiadada de los ritmos de actividad que dicta la racionalización del rendimiento. Así se explica la energía con que las bases sindicales — que se van erigiendo- denuncian los abusos del poder de organización que, bajo el santo y seña de la productividad, persigue una plusvalía tan abominable como imperceptible. El nuevo sindicato aglutina, de modo espontáneo y consciente, a las personas físicas que, en régimen de democracia directa, defienden los intereses colectivos atacados por el poder empresarial. Nadie ignora las deficiencias de estructura del experimento asambleario, afectado por la lentitud que sus inexpertos agentes transmiten a los procesos de formación de la voluntad colectiva y a la toma de sus decisiones. Resulta, aconsejable que el sindicato asambleario - expresión de un estado de conciencia inherente a esos intereses colectivos - ceda su puesto a la organización reflexiva de las representaciones unitarias que operan en régimen de democracia delegada. No es acertado denegar a estas representaciones la calificación de sindicatos y el carácter de sujetos activos de las libertades que, como tales, les corresponde ejercitar (arts. 7 y 129.2 CE).

También son sindicatos los grupos de trabajadores cuyos objetivos carecen, no obstante la importancia de sus requerimientos, de perspectiva duradera, porque su acción se circunscribe al tiempo necesario para amparar unos intereses colectivos que no exigen compromisos in- 
definidos de futuro. Como el valor superior del pluralismo político deja al legislador positivo en libertad de establecer, llegado el caso, el modelo de sindicato preferible, sorprende que los sindicatos temporales sólo tengan la oportunidad procesal de intervenir, como uniones de hecho sin personalidad, en las contiendas planteadas ante el orden social de la jurisdicción. El reconocimiento del interés colectivo litigioso se ciñe al tiempo indispensable para su protección y determina una tutela judicial garantizada con el acceso al juez ordinario predeterminado en la ley. Se echa de menos la regulación - material y exhaustiva- de esta variante sindical, huérfana de un Derecho sustantivo que estime la frecuencia y habitualidad con que las relaciones industriales se sirven de su auxilio (arts. 7 CE y 12 LPL).

\section{Repercusiones del pluralismo político en el Derecho Social}

La mención del valor superior del pluralismo político significa, en la latitud del deber ser, que las inspiraciones ideológicas de corte sindical que acompañan a cualquier Política Social - aún distinta de las que, compartiendo líneas de fuerza comunes, ofrecen rasgos diferenciales y competitivos- facilitan su traslación a los respectivos programas. Pese a lo lógico de sus disidencias horizontales, cada una de dichas políticas conserva, a la hora de verificar sus ofertas, la constitucionalidad vertical que se sigue del acierto con que aquel valor se ha manejado y de la utilidad que del mismo se espera (art. 1.1 CE).

El dato de que los partidos políticos expresen el pluralismo político, no ciega otros cauces circulatorios de sus versiones y mensajes. Semejante expresión —entendida a la luz de un sentimiento mínimamente liberal- no entraña afán alguno de acaparamiento y constituye la manifestación natural de una concurrencia pluralista que no desautoriza otras propuestas. La tarea de contribuir — que delimita el contenido y ejercicio de la libertad sindical colectiva - sindicaliza la sustitución o suplencia de unas iniciativas que, ante lo creciente y complejo de las realidades sociales, los partidos políticos no pueden afrontar. Lo mismo cabe decir de ciertos fines que, debido a las dificultades advenidas, recaban la cooperación del sindicato que, por naturaleza y sin espíritu de protagonismo, se convierte en un agente social cuya contribución es indispensable para conseguirlos (arts. 1.1, 6, 7, 9.2 y 28.1 CE).

Los intereses que, en régimen de contribución, promueven y defienden las organizaciones sindicales, son intereses de naturaleza económica. No sólo afectan a la causa del mundo del trabajo, de cuyo beneficio se trata, sino que también pueblan el campo de las exigencias 
de la economía general, servida por las funciones sociales anejas al ejercicio de la libertad sindical. Igualmente incluyen los intereses sociales, porque - ante el desafío que el constituyente ha dirigido a un sindicato ávido de oportunidades participativas - sus organizaciones se ocupan de cuanto signifique conexión o tangencia con los intereses de los trabajadores. No importa que éstos compartan sus inquietudes y su suerte con otros protagonistas -individuales y/o colectivos- de la escena social. La tesis que propugna la suplencia de los partidos políticos por la mediación de las libertades sindicales —en su acepción más comprensiva - da idea de la fuerza expansiva que el pluralismo político recibe del constituyente. Aunque nada más se diga al respecto, la naturaleza de las cosas hace el resto y ratifica estas reflexiones (arts. 7, 28.1 y cap. $3 .^{\circ}$, tit. I CE).

\section{Ambientación constitucional de las libertades sindicales}

Las organizaciones sindicales - cuyas libertades individuales y colectivas se ejercitan en el territorio de los Estados soberanos- no están sujetas a su ordenamiento jurídico, ni tienen que adecuar sus conductas a su Derecho positivo. La sujeción querría decir, llegado el caso, que la voluntad del sindicato ha de ceder ante las normas que, al emanar del Estado, la sustituyen de un hipotético deber de acatamiento. Tal es el signo de los mandatos y/o prohibiciones que convergen en ese ordenamiento. El deber de respeto al texto constitucional y al resto del ordenamiento jurídico difiere conceptualmente de la sujeción, porque — $\tan$ pronto como la soberanía sindical se consolida y demuestra su aptitud creadora de un ordenamiento jurídico extraestatal- hay que evitar las ingerencias de éste — dotado de una base institucional — en la órbita del Derecho estatal — de base territorial - con el que, previa interacción de las medidas de control y de apoyo, está destinado a convivir (arts. 6, 7 y $9.1 \mathrm{CE}$ ).

La opinión disidente sostiene - contra los rudimentos de la teoría general del Derecho- la existencia de relaciones de subordinación o dependencia entre normas estatales y extraestatales, siendo así que su génesis, a partir de los respectivos ordenamientos jurídicos, lo desautoriza. Las fricciones o contactos anómalos - que pueden darse entre el Derecho estatal y el nacido de la autonomía colectiva- no encajan en el régimen del principio de jerarquía normativa. Principio que sólo interviene cuando se discute la subordinación o prioridad de normas pertenecientes al mismo ordenamiento jurídico y no a ordenamientos jurídicos distintos. Ello exige que, dentro del círculo común de generación, 
se dejen de aplicar las reglas que, siendo de rango inferior, contradigan o se aparten de lo dispuesto en otras de jerarquía superior. Ejemplo tópico del error denunciado es afirmar que la ley del Estado prevalece sobre el contenido normativo de la negociación colectiva, gracias a un principio de jerarquía normativa que, según lo arguido, carece de aplicación al caso (arts. 7, 9.3 y 37.1 CE).

La libertad sindical colectiva - que, a primera vista, conviene sólo a los sindicatos de trabajadores - se extiende a las relaciones de empleo del sector público. La fuerza expansiva del Derecho Sindical o, si se quiere, el ímpetu histórico de su soberanía, le llevan a ocupar parcelas que el constituyente no ha convertido en reductos herméticos. Una de las reformas informales del texto constitucional ha consistido en ensanchar el ámbito de las libertades sindicales - aumentando las variantes de su autonomía y multiplicando el esfuerzo de colmar el ordenamiento jurídico extraestatal con las adquisiciones de la negociación colectiva - y en vulnerar la fortaleza, inmune hasta entonces, que los conceptos clásicos de indisponibilidad y jerarquía mantenían en las tradicionales relaciones de servicio de las Administraciones Públicas (arts. 37.1 y 103.1 CE).

Los acuerdos interprofesionales del sector público, representan - conforme a la nomenclatura sindical que cuida de la propaganda de sus éxitos- ejemplos de leyes pactadas. Cuídase así de destacar el triunfo del poder sindical sobre un Estado formalmente soberano que, ante lo perentorio de las circunstancias, accede a formas materiales de negociación que pugnan con su naturaleza, aunque se compromete a traducir, no sin utilidad, su resultado en normas jurídicas que formalmente emanan de la acción parlamentaria. Quiérase o no, estas transacciones erosionan los poderes de la soberanía parlamentaria, que legisla, o de la autonomía gubernamental competente para el desarrollo reglamentario de las leyes (arts. 7, 37.1, 66.2, 97 y 103.1 CE).

\section{Adelanto y estímulo de las libertades sindicales}

La definición de la libertad sindical colectiva como acción de contribuir, denota - ante la utilización intencional del modo del verboque, lejos de conducirse en solitario, la movilidad sindical aconseja posturas de cooperación. La principal de ellas - completada con el auxilio de otros agentes sociales que la perfeccionan- equivale a la promoción y defensa de los intereses de los trabajadores, cuyos compartimentos son varios. Hay intereses que, afectando de antiguo a la protección profesional, acusan las mudanzas de las nociones de alieni- 
dad y dependencia en el marco de las relaciones individuales de trabajo. Otros intereses atañen a proyectos que los trabajadores -investidos del estado civil de ciudadanos - comparten con el resto de los agentes sociales. Este diseño ratifica, una vez más y por vía del esfuerzo de transformación, la conocida máxima que subrayaba el ascenso de la condición deprimida de súbdito a la cualidad superior de ciudadano. Se computan, en fin, los intereses costosamente aprehensibles, diseminados o difusos, cuya tutela, no obstante los entorpecimientos de alguna magnitud, invita a desplegar la máxima inventiva que los estabilice (arts. 7 y $9.2 \mathrm{CE}$ ).

La variante de contribución más reciente, que parece accesoria o novedosa, consiste en el acceso del sindicato a los aspectos de la vida social que — siéndole ajenos hasta entonces - recaban su cooperación y le gravan con obligaciones que derivan de esa circunstancia. Trátase de deberes inherentes al decisionismo expansivo de las organizaciones sindicales, al apoyo de los poderes públicos al ejercicio de sus libertades, y a las acciones de cooperación innominada que, para completar sus compromisos, el sindicato emprende en el marco de las realidades sociales que le salen al paso art. 7 y cap. $3 .^{\circ}$, tit. I CE).

La gestión de los intereses de los sindicatos en el periodo histórico de la prosperidad y plena ocupación, mostraba el entusiasmo despertado por el éxito del principio de irregresividad de las adquisiciones sociales, plasmado en la lúcida máxima que, para resaltar la irrevocabilidad de sus conquistas, rezaba «... siempre más, nunca bastante...». De ahí, la intangibilidad que, como derechos adquiridos, lograron los avances de los sindicatos en las peripecias - controvertidas y escabrosas- del conflicto industrial. La gestión sindical de los intereses afectados por la incoación de la crisis económica, desencadena - ante el abuso de los mecanismos de la flexibilidad y la desregulación, y la tendencia a disfrazar la recivilización del Derecho Social- las soluciones defensivas que, ante la dureza de los sacrificios impuestos, el sindicato tuvo que aceptar sin alternativas honorables. Se desistió del - hasta entonces incólume- principio de irreversibilidad de las conquistas sociales ya consolidadas, y se afrontaron, con entereza, los desgastes que el fenómeno mundializador causaba en los frentes residuales de la actividad del sindicato (arts. 7, 28.1, 37.1 y 129.2 CE).

La defensa de los intereses económicos de los sindicatos garantiza los recursos vitales de los trabajadores, el crecimiento de su poder de hecho, y las tentativas de controlar el ejercicio de la libertad de empresa y la Política Económica del Estado. He ahí la comprensión de lo que su acción de contribuir es y significa, y la clave de su vocación de ocupar con legitimidad — nunca de invadir - los espacios que la natu- 
raleza de las cosas sitúa en las inmediaciones de una reacción sindical ilustrada y activa. Reacción que se da en esos pagos cumplir las funciones sociales que espera de ella el reto constitucional y agrandar el campo de su autorregulación. La libertad sindical es, por excelencia, el modelo de derecho inquieto que, a impulso de su voluntad salvífica, no recata el afán de extenderse a horizontes muy varios. Desalienta advertir el abismo que se abre entre la simplicidad de las reacciones sindicales y la complejidad de las que, sin demérito de su intervención eficaz, puede y debe asumir el sindicato - aunque no siempre lo hagacon la fuerza moral que le imprimen su autonomía y su relieve constitucional (arts. 33.3, 38 y 128.1 CE).

Los llamados intereses propios de los trabajadores, son tales a la luz de criterios interpretativos, que ponen de relieve los aspectos mecanicista y finalista del concepto. Merecen ese nombre, en la primera de ambas acepciones, los que - a lo largo de la historia y el éxito de las acciones sindicales - se han ido acumulando para hacer balance de las conquistas sociales obtenidas. Conforme al segundo de dichos pareceres, el adjetivo propios desborda un entendimiento literal —basado en la enumeración de los derechos adquiridos- y pasa a reflejar la intensidad con que la voluntad sindical se aplica a nuevos y originales objetivos. A saber, los de hacer suyas — dotándoles del remedio adecuado- cuantas situaciones sociales conectan con el compromiso protector de las iniciativas sindicales. Los intereses propios no sólo son los avalados por el proceso histórico de acaparamiento y exclusividad, sino también los apropiables mediante el diagnóstico que el sindicato hace de su fisonomía. Diagnóstico obediente, si es del caso, al llamamiento de sectores sociales que, al reclamar la protección de intereses desatendidos u olvidados, atraen la curiosidad del sindicato que ensaya una terapia de sus vicisitudes. Diagnóstico que, otras veces, realiza el mismo sindicato para suplir el desconocimiento, la indiferencia, la apatía o la dificultad de movimientos del grupo social afectado. Así se exhuman las situaciones necesitadas de tutela, se informa verazmente a las personas y grupos inmersos en su conjunto de problemas, y se planifica una estrategia consecuente con la determinación sindical de resolverlos (arts. 1.1, 7 y $9.2 \mathrm{CE}$ ).

La libertad colectiva del sindicato clásico — cuya inquietud obliga a definiciones ambiciosas - se completa con la ordenación sistemática de las especies de la libertad sindical individual en los sectores público y privado, con las acciones de control y de apoyo a la negociación colectiva, que edifica el ordenamiento jurídico extraestatal, y con las vías que - en los procesos comunes de organización de las unidades productivas - han abierto las representaciones unitarias de los trabajado- 
res. No huelga censurar la hostilidad larvada que, denegando a estas últimas la condición de titulares de sujetos de aquellas libertades, les retira la legitimación activa necesaria para entablar el recurso de amparo constitucional. Algo contradictorio con la recepción de un sindicalismo dual que, tiempo atrás, se consideró equitativo y saludable (arts. 7, 28.1, 37.1, 53.2, 129.2 y cap. $3 .^{\circ}$, tit. I CE).

\section{Interacciones del ordenamiento sindical y el ordenamiento jurídico del Estado}

El deber de respeto de los sindicatos al ordenamiento jurídico del Estado difiere del deber de sujeción que, ante la duplicidad de ordenamientos jurídicos, carece de razón de ser. Revela el provecho de las reglas de juego que exigen estar a las medidas de control y de apoyo que el Estado adopta en presencia de las libertades sindicales. Lo primero, porque la entrada del sindicato en su circunscripción territorial - aunque obedezca a la emergencia de una libertad irresistiblemente protegida por el Derecho de Gentes que la engendra- no justifica la irrupción, sin condiciones, en el espacio que es objeto de una toma de posesión cualificada. Lo contrario sancionaría la victoria de la soberanía institucional sobre una soberanía territorial desarmada y vencida. El sindicato se pliega, puesto que le son útiles, a las acciones de control que -inspiradas en la flexibilidad o en el recelo - no vulneran su libertad más allá de lo razonable. Lo cual exige instrumentar las acciones de apoyo que, de una parte, disponen las circunstancias favorables a una libertad sindical efectiva, y, de otra, suprimen los entorpecimientos que frenan su efectividad. Los sindicatos no ignoran que - además de lo eficaz de sus medios y lo contundente de sus tácticas - hay aspectos de sus actividades que deben completarse. Prescindir del apoyo estatal - que compensa la carga de las intervenciones de control- no es una opción libérrima de la soberanía sindical, sino una prueba de ligereza desautorizada por los signos de los tiempos. Constituye un error sustancial sobre la base del negocio o presuposición de la movilidad del sindicato frente al Estado que ha cumplido la obligación éticopolítica de acogerle. Aceptar las medidas de apoyo es adoptar una postura positiva y fructífera, porque siempre perduran la duda y el reproche de no haber agotado el descenso al fondo de las cosas para esclarecer esas situaciones y graduar la dosis de libertad que necesitan (arts. 7, 9.2 y 28.1 CE).

La democraticidad del sindicato explica que, a imitación del Estado social y democrático de Derecho en que tiene cabida, su estructura no se concibe si la existencia de un poder normativo o estatutario, que 
marca las directrices de un régimen de democracia delegada, un poder de administración de los acontecimientos cotidianos y un sistema interno de solución de conflictos (arts. 1.1, 6 y 7 CE).

La autonomía sindical se entiende sin perjuicio del carácter institucional del sindicato y de un asentamiento territorial que condiciona las funciones de control y de apoyo a que el poder estatal se compromete (arts. 7 y $9.2 \mathrm{CE}$ ).

El funcionamiento democrático del sindicato requiere observar las reglas de juego que, más o menos explícitamente, se adoptaron cuando, urgido por lo imprevisible de los cambios políticosociales, el sindicato prefirió desistir de sus — cada vez más discutibles y caducas - ambiciones revolucionarias. El Estado social y democrático de Derecho rechazó el regreso a los antagonismos — demoledores y estériles- de la lucha de clases y optó por la ventaja de las fórmulas que, normalizando el conflicto industrial, eliminaban sus tensiones desarregladas o excesivas. Se comprende que - ante la oferta de tan sugestivo futuro- el sindicato adquiriese la cualidad de interlocutor válido frente a los poderes públicos del Estado soberano - con los que había mantenido fricciones muy álgidas - y los poderes de hecho empresariales, predispuestos a los contactos sociales y económicos que eran propios de ese nuevo escenario (arts. 7, 9.2, 10.1, 28.1 y $38 \mathrm{CE}$ ).

Hay una separación evidente entre el ordenamiento del Estado - debido a la concepción piramidal de un sistema de normas jerárquicamente dispuesto- y el ordenamiento extraestatal que, con el ejercicio de la autonomía colectiva, consolida la imagen del poder sindical. De esa duplicidad son consecuencia las alusiones al primero de ambos como continente del valor superior del ordenamiento jurídico, título de sujeción de los ciudadanos y los poderes públicos, y absorbente de la legislación estatutaria autonómica. De ello dan testimonio los mecanismos de control y de apoyo a la negociación colectiva, modelo de ejercicio de la libertad sindical y fuente del Derecho objetivo que sus principios y preceptos incluyen (arts. 1.1, 7, 9.1 y 2, 28.1, 37.1 y 147.1 CE).

\section{Perpetuación de la cláusula transformadora y social}

Los ecos de la cláusula transformadora y social — que, en vez de encabezar el texto constitucional, debió haber completado la proclamación de la igualdad material y las interdicciones de discriminaciónresuenan en los pasajes de la ley fundamental que acusan su influencia. Para evitar las debilidades y tibiezas de un compromiso de alta intensi$\mathrm{dad}$, ha sido necesario rehacer figuras ajustadas a los radicalismos éti- 
cos que, en principio, parecían inseparables del entendimiento de esa cláusula (arts. 3 II CI, 9.2, 14 y cap. 3. ${ }^{\circ}$, tit. I CE).

Se propuso, en principio, eliminar la situación depresiva de cualesquiera ciudadanos frente a los poderes de dominación que les degradaban en una sociedad cuya clave de prosperidad era la plena ocupación. El objetivo posterior - inherente a las servidumbres del Derecho Social de la crisis económica - consistió en evitar la retirada o absentismo de la libertad de empresa en una economía de mercado, y en arbitrar instituciones de promoción y de fomento. El bloque de funciones sociales se impuso a fin de asegurar el crecimiento de la riqueza, de mantener los servicios esenciales de la comunidad y de evitar la degradación del empleo. Un objetivo que - vigente hoy día y justificado por la lucha contra los efectos perversos de la mundialización- habría permitido combatir la falsa recivilización del Derecho Social y apartar los obstáculos a la recuperación de las ventajas sociales sacrificadas - acaso estérilmente- en las fases de aparición de la crisis económica, de contemporización con sus episodios y de inmersión final en sus dificultades (arts. 9.2, 38, 40 y 129.1 CE).

La preferencia por la paz social - coincidente con el concepto tradicional de orden público - da a entender que la contribución esperada de los sindicatos lleva consigo su renuncia a la revolución y su disponibilidad cooperativa al estado de cosas que se les implica. Las libertades sindicales no pueden ejercitarse en solitario, porque la acción transformadora del Estado - consciente de las dificultades con que su despliegue tropieza - tiene que dispensarle su apoyo. Las libertades sindicales comparecen también en otros ámbitos que, siéndoles hasta el momento ajenos, ocupan por derecho propio y que están habitados — si no del todo, sí que mayoritariamente- por contingentes de trabajadores a los que el sindicato no escatima su solicitud. Las consecuencias de su actividad amparan, por irradiación, a personas y grupos sociales situados fuera del mundo del trabajo (arts. 7, 9.2 y 10.1 CE).

Las eventuales rupturas de la paz social — que el sindicato acuerda en situaciones límite- no expresan el ejercicio de una soberanía sin fronteras. No es prudente alargarlas más allá de lo indispensable y aplazar la restauración de la paz social deteriorada, que abarca los requerimientos de la coexistencia, la colaboración y la coparticipación. De lo contrario, la dignidad de la persona humana se expone a enormes riesgos, incluida la pérdida de las adquisiciones habidas al precio de considerables sacrificios. La dignidad de la persona es un crédito asignado al individuo en pro del íntegro desarrollo de su personalidad, tutelado por el ordenamiento jurídico y dependiente de unos derechos subjetivos cuya colimitación prohibe que los unos invadan la esfera de 
los otros. Cuando los sindicatos - siquiera sea temporalmente- transforman la sociedad organizada en una comunidad cuyo pluralismo se esfuma, el crédito de la dignidad se ve frustrado ante el fracaso de los servicios esenciales de la comunidad. El adjetivo esenciales no designa la utilidad del sustantivo, sino que se refiere al ser o no ser de las comunidades en que los valores de la dignidad del individuo han corrido esa suerte (arts. 1.1, 10.1, 28.2 y 37.2 CE).

El razonable entendimiento de recientes normas del Derecho Social comunitario justifica la elevación de los derechos sociales a la categoría de derechos fundamentales. Su contenido esencial o núcleo invulnerable ha de ser integrado, si se aprecian defectos o lagunas, o interpretado, si su entendimiento parece difícil o confuso. El acervo de proclamaciones que, sobre el Derecho de Gentes de las relaciones de trabajo, generan los organismos e instituciones internacionales, da idea de la abundancia de las normas que facilitan esas operaciones (arts. 136 I, 137.3, 140 y 143.1 VCTR, 9.2 y $10.2 \mathrm{CE}$ ).

La simultánea invocación de los conceptos — defendibles y coexistentes- que representan el orden político y la paz social, muestra la predilección por las formulas encaminadas a lograr la distensión normalizada del conflicto industrial. Las contradicciones de los factores económicos y humanos de la producción son inevitables y, como sustitutivo racional de la esterilidad de la lucha de clases, están en la naturaleza de las cosas. Sus divergencias no pueden alcanzar cotas de exacerbación que - yendo más lejos del equilibrio inestable que les caracteriza - hagan peligrar el orden público y la coherencia de una sociedad cuya disolución es mas que probable si se abandonan esas reglas de juego (arts. 9.2, 10.2, 28.2 y $37.2 \mathrm{CE}$ ).

\section{Dinamismo de la transformación}

La promesa de erigir una sociedad democrática avanzada pugnaba con la elasticidad y el pluralismo constitucionales, porque los autores de la ley fundamental no redactaron el preámbulo que la precedía. El cambio rotundo que esa introducción insinúa, se sustituye por la cláusula transformadora y social que viene de un mensaje pensado para emancipar al mundo del trabajo en el área de la industrialización con economía de mercado. Las relaciones individuales y colectivas de trabajo se han beneficiado de un compromiso que promueve la igualdad y libertad de sus protagonistas, y suprime los obstáculos que puedan impedirlo. El legislador ordinario no está directamente vinculado por el deber de promulgar normas de apoyo en materia de Política Social, 
pero su margen de decisionismo político le permite apelar — si así se lo propone- de la cláusula de transformación. Su resonancia consta en numerosos pasajes del texto constitucional, pues pertenece a un pacto germinal que el constituyente respeta y no ha olvidado, aunque, en algunas ocasiones, decaiga su memoria (dec. 5 Pr. CE y 9.2 CE).

Si se pretende llegar a los niveles óptimos que la cláusula transformadora y social autoriza, la Política Social gana en la calidad que, para bien de todos, se desliga de la neutralidad funesta y elige la beligerancia de la revolución desde lo alto (arts. 1.1 y 9.2 CE).

Esta cláusula se habría vigorizado plenamente, si, en vez de incorporarse al preclaro pasaje que le ha dado acogida, fuese parte del material de artillería que contienen la interdicción de discriminación y el reconocimiento del derecho material a la igualdad. Su posición intencionada permite opciones de intensidad variable, pero no impone -ineludiblemente y por sistema - las orientaciones radicales que se esperaban de sus antecedentes históricos y en las que había depositadas no pocas esperanzas. El alcance transformador de su proclamación se concibió en clave de una prosperidad apta para primar los intereses marginados de la clase trabajadora. Más adelante, las incidencias de la crisis económica y la notabilidad de las funciones sociales de la libertad de empresa, justifican que el propósito transformador esté al servicio de unos y otros (arts. 9.2, 28.2 y $38 \mathrm{CE}$ ).

La ingerencia del Estado en la vida económica determina que sus potestades normativas establezcan limitaciones de orden público y armonicen los adelantos de la Política Social con las necesidades de la economía general. Esta, que no prima incondicionalmente sobre aquélla, tampoco ha de quedar expuesta a riesgos excesivos o menoscabos desproporcionados. Incluso se suscita el problema de si —además de establecer y dirigir las políticas orientadas al pleno empleo- los poderes públicos son titulares del derecho fundamental en que, pese a la modestia de su enclave constitucional originario, se ha convertido en la libertad de empresa. Su ascenso es consecuencia de la primacía del Derecho Comunitario europeo y del apoyo que le prestan el reconocimiento y protección del derecho a la producción y creación científica y técnica (arts. 9.2, $20.1 b, 38$ y $128.2 \mathrm{CE}$ ).

\section{Reflejo constitucional de la autotutela colectiva}

El derecho de huelga de los trabajadores, para la defensa de sus intereses, refleja la elevación de la libertad sindical a la segunda potencia y la conversión de la autonomía sindical en autotutela o potestad 
de defenderse a sí mismo. La huelga general — que, augurando la solución final que los sindicatos anunciaban conminaban al Estado demoliberal, ponía en escena su trauma revolucionario- evidencia un poder sindical que, siquiera por tiempo limitado, exhibe hoy, ante el Estado social y democrático de Derecho, su aptitud para retrotraer la sociedad al estado de cosas anterior a la conclusión del pacto social (arts. 9.2 y 28.2 CE).

A diferencia de otros casos en que el desarrollo legislativo del derecho constitucional es obligatorio y expreso, el constituyente ha admitido - sin que los trabajos preparatorios informen sobre la alteración del modo del verbo- dos opciones igualmente admisibles, a saber, la regulación legislativa del derecho de huelga o la sustitución de este arbitrio por la autorregulación de la huelga a cargo del poder sindical (art. 28.2 CE).

Sin detrimento del contenido esencial del derecho de huelga, parece aconsejable instituir una acción declarativa de la legalidad o ilegalidad de esta forma de presión institucionalizada. Así quedan resueltas las cuestiones previas que, acabada la huelga, se debaten en numerosos procesos individuales y que, a falta de esa solución preventiva, engendran inconvenientes múltiples. Determinan calificaciones contradictorias del hecho colectivo y vulneran el principio ontológico de no contradicción, admitiendo que una cosa pueda ser y dejar de ser al mismo tiempo. Contradicen, no menos, la seguridad jurídica y los objetivos del derecho fundamental a la efectiva tutela judicial, incompatible con la dispersión y el incierto destino de los intereses relacionados con los efectos de la huelga (arts. 9.3, 24.1 y 28.2 CE).

El mantenimiento de los servicios esenciales de la comunidad en caso de huelga, no significa la conservación de unos mínimos elementales o muy rudimentarios. Tiende a reemplazar la actividad de los huelguistas por los medios con que el poder público ha de reducir a su medida justa las consecuencias de la huelga. Sólo así es evitable la producción de daños extralimitados y ajenos a los fines de la autotutela sindical. Queda en pie la regla de oro -incumplida en la generalidad de los casos- de que el ejercicio regular y tempestivo del derecho de huelga no ha de causar más daños que los derivados de la falta de contribución de la fuerza de trabajo que entonces se deniega. Los componentes emocionales e incontrolables de la huelga hacen, de todo punto, impracticable la prudencia teórica con que se ha formulado ese criterio (arts. 10.1 y $28.2 \mathrm{CE}$ ).

El reconocimiento de la libertad de empresa como derecho fundamental, puede modificar la clásica estrategia del cierre patronal. Superada su naturaleza de medida de autotutela utilizable en último lugar, se 
convertiría en un instrumento de ataque que, conforme a la doctrina de la paridad de los instrumentos de lucha, aumentaría los desequilibrios de un conflicto industrial que las corrientes mundializadoras amenazan de disolución (arts. 9.2, 37.2 CE y 43 I y 56.1 VCTR).

\section{Conclusión}

Las repercusiones constitucionales del Derecho Social colectivo se deben a su continuidad procesológica, más densa que en otros sectores del ordenamiento jurídico, y al frecuente acceso de sus temas al recurso de amparo. Su atractivo invita a explotar un yacimiento inagotable de conjeturas y problemas, cuyo análisis interdisciplinar exige la asistencia de saberes ajenos al Derecho y la sensibilidad de sus operaciones de síntesis. Por ahí discurren las expectativas de un Derecho Social que no desiste de rehacer sus ritmos de crecimiento y de progreso, aunque las circunstancias socioeconómicas de hoy le sean hostiles y las consignas mundializadoras propicien las operaciones de su voladura controlada.

\section{Abreviaturas y siglas}

art. artículo.

cap. capítulo.

CCDSFT Carta Comunitaria de los Derechos Sociales Fundamentales de los Trabajadores de 8 y 9.12.(9)89.

CE Constitución española de 27.12.(9)78.

CI Constitución italiana de 27.12.(9)47.

CSE Carta Social Europea de 18.10.(9)61.

LPE Ley de Procedimiento Laboral (RD.Leg. 7.4.(9)95)

Pr. Preámbulo.

tít. título.

UE Unión Europea.

VCTR Versión Consolidada del Tratado de Roma modificado por el Tratado de Amsterdam de 2.10.(9)97. 